\title{
Factors Related to Quality of Life in Treatment-Adherent, Successfully Treated HIV Patients in France
}

\author{
José Côté $^{*}, 1$, Philippe Delmas ${ }^{*}, 2$, Cyrille Delpierre ${ }^{3}$, Hélène Sylvain ${ }^{4}$, Simone Delon $^{3}$ and \\ Geneviève Rouleau ${ }^{1}$ \\ ${ }^{1}$ University of Montreal, Canada \\ ${ }^{2}$ Hospital of Paris (AP-HP), France \\ ${ }^{3}$ Hospital of Toulouse, France \\ ${ }^{4}$ University of Quebec-Rimouski, Canada
}

\begin{abstract}
The objectives of this study were to document the psychosocial characteristics of treatment-adherent, successfully treated HIV patients and to examine the relationships between psychosocial variables. The sample was composed of 133 persons living with HIV, with optimal adherence to antiretroviral therapy and with no detectable viral load. The psychosocial profile of the cohort showed that participants had moderate levels of stress, used a wide range of strategies to adjust to their situation and perceived their social support to be good. As well, they evaluated their quality of life (Medical Outcome Study-HIV) as moderate. Quality of life in psychological domain is largely explained by perceived stress $(53 \%)$. Quality of life in physical domain is largely dependent on discomfort reported arising from HIV-associated symptoms and treatment (39\%). Findings suggest that treatment-adherent, successfully treated patients with HIV are still a fragile population, and that it is essential to provide interventions that reinforce their ways of coping.
\end{abstract}

Keywords: Persons living with HIV, quality of life, adherence, stress-coping, social support.

\section{INTRODUCTION}

In spite of the advent of new treatments, infection with the human immunodeficiency virus (HIV) is still a major public health preoccupation. The epidemic began about 20 years ago and, since then, more than 33 million people have been infected by the virus in 2007 [1]. The epidemic continues to spread extremely rapidly in Central Asia, South Africa, Latin America and the Caribbean countries. In western countries new combinations of antiretroviral drugs have transformed the daily life of HIV persons. Although, they are no longer confronted with a rapid and fatal prognosis, they still have to cope with living with a chronic disease [2].

The administration of antiretroviral therapy (ART) has increased since its introduction in 1996. At present, $94 \%$ of HIV patients living in western countries are estimated to have access to such treatment [3]. The beneficial effect of these new treatments on viral load and CD4 levels has made a considerable contribution to improving patients' state of health and reducing morbidity, mortality and hospitalization [4]. Nevertheless, living with HIV is still a constant challenge. As well as facing the problems related to chronic disease, the person living with HIV has to adjust to a complex and changing treatment regimen and adhere to it.

*Address correspondence to these authors at the (JC) University of Montreal, C.P. 6128, Succursale Centre-Ville, Montréal, Québec, H3C 3J7, Canada; Tel: (514) 343-7156; Fax: (514) 343-2306;

E-mail: jose.cote@umontreal.ca and (PD) Hospital of Paris (Cochin), 27 rue du Faubourg Saint Jacques, 75014, Paris, France; Tel: + 33 (0)1 584131 91; Fax: + 33 (0)1 5841 10 95; E-mail: philippe.delmas@cch.aphp.fr
For several years now, there has been a considerable improvement in ART and regimens with fewer pills to take, taking those less often are now available and they involve fewer meal restrictions [5]. However, the impact of this therapy on his or her quality of life can be significant and it is a variable of paramount importance amongst this population [6] and one which deserves closer investigation.

Quality of life is a multi-dimensional construct $[7,8]$ that refers to physical, psychological and social aspects of an individual. These are indicators of how well an individual functions in daily life as well as of how the individual's perceptions of how health status influences his or her life. Johnson, Catz, Remien et al. [8] stress that the concept of quality of life is an important result variable that is used in clinical trials, cost-effectiveness studies and research exploring quality of care. In fact, quality of life has emerged as a significant outcome measure in the context of chronic disease, in particular among persons living with HIV [9]. Earlier studies, conducted prior to the introduction of antiretroviral therapy, showed a pattern of deterioration in quality of life over time; this was particularly evident for those with physical impairment $[10,11]$. Since the advent of antiretroviral therapy, the general trend shows little change or a modest improvement in quality of life. Burgoyne and colleagues [12] evaluated changes in quality of life over a four-year period among 41 adult outpatients living with HIV, most of whom were consistently on antiretroviral therapy. They reported that quality of life was generally stable or slightly improved over time, for the overall sample. In a more recent study, Mannheimer, Matts, Telzak et al. [9] reported significant improvements in quality of life after one 
to four months of treatment with the antiretroviral therapy, and that this persisted at 12 months.

It is an advantage for both clinicians and researchers to have a better understanding of factors that may improve quality of life for HIV persons [6]. As mentioned by Stangl and colleagues [13] a precursor to improving QoL is knowledge of the factors that influence it, upon which appropriate interventions could be developed. The psychosocial variables most frequently related to their quality of life are social support [14-18] coping strategies $[17,19,20]$ and psychological status $[18,21,22]$. Before the introduction of antiretroviral therapy, CD4 cell counts [23] and HIV disease stage [24] were the factors most frequently related to quality of life. Burgoyne's [12] results indicate that quality of life is currently less sensitive to immunologic and virologic changes than to symptom changes. Mannheimer and colleagues [9] have also recently emphasized the possible contributing role of treatment adherence in explaining the quality of life of persons living with HIV. Although researchers are increasingly interested in gaining a better understanding of contributing quality of life factors in HIV persons [25], ambiguities continue to persist.

Few studies seem to have documented the experience of persons who apparently succeed with daily therapy. As such, it is timely to investigate factors determining quality of life in a population of patients who adhere to treatment and whose treatment is effective. Using a salutogenic approach confers both originality and value added to this avenue of study. Briefly, the knowledge that people viewed as "nonproblem' have recourse to in dealing with and resolving problematic situations they encounter can be a starting point for setting up new techniques for taking charge and for prevention.

\section{THEORETICAL MODEL OF STRESS COPING}

In order to guide the selection of the explanatory variables for quality of life, we selected a theoretical model of stress/coping, developed by Lazarus and Folkman [26]. Integrated in a transactional approach to stress, it gives a major emphasis to cognitive evaluation of the stressful situation, relying on both primary and secondary appraisals. Primary appraisal refers to the individual's initial perception of an event: it may be considered as trivial (without significance), a loss (bodily, material, relational), a threat (prospect of loss) or a challenge (prospect of benefit). When the event is perceived as a loss or a threat and is therefore stressful, the individual experiences negative emotions such as shame or anger. The individual then shifts into secondary appraisal, weighing up what can be done to cope with the threat or avoid harm, and speculating on the potential for gain. Following primary and secondary appraisal, the individual chooses the appropriate coping options. Such a theoretical framework of primary and secondary appraisal is strongly recommended in looking at the problems that people living with a chronic illness experience [6]. It allows us to gain a full appreciation of the different ways individuals adapt to a situation they perceive to be stressful.

Living with HIV means that every day it is necessary to come to terms with a stigmatizing disease with distinct constraints. According the Lazarus and Folkman theory [26], the individual's personal appraisal of this situation will have repercussions on the way he or she adjusts to the condition and eventually on his or her ultimate quality of life. We used their theoretical model [26] to identify the different variables in our study as follows: the stress of living with HIV, physical symptoms experienced, coping strategies used, coping resources available in the form of perceived support, and quality of life (Fig. 1).

\section{RESEARCH OBJECTIVE}

The objectives of this study were to document the psychosocial characteristics of treatment-adherent, successfully treated HIV patients and to examine the relationships between stress experienced, discomfort reported arising from HIV-associated symptoms and treatment, perceived social support, coping strategies used, and quality of life. We performed our study with a cohort of successfully treated patients in France living with HIV.

\section{METHODS}

\section{Design and Study Population}

Our "Promosud" study was conducted in six HIV units in the south-west of France, where we followed a cohort of HIV-infected persons of the course of a year. Participants were included over a six-month period (second semester of 2004) and were all adherents at inclusion. As recommended in French national guidelines [27] the measure of adherence combined objective and subjective evaluations and was determined from a self-reported questionnaire and the measurement of viral load. A person was considered as adherent if he or she met two criteria: a viral load of 50 copies or less, which is the standard threshold used in the various centres, and a $95 \%$ adherence rate reported on the questionnaire in the last seven days [28]. We selected a convenience sample of 147 persons and ultimately obtained complete data for 133 individuals. Sample size was compatible with the requirements of statistical analysis (twotailed alpha risk $5 \%$, study power $80 \%$, SD 20 ). We used two exclusion criteria: either uncontrolled psychiatric problems or a neurological disorder affecting the person's ability to participate (e.g., cerebral toxoplasmosis).

\section{Measurement}

Various measurement tools were used in this study some for respondent selection and others for measuring the variables selected.

\section{Instruments for Selecting Respondents}

We evaluated treatment adherence by two means: measurement of viral load and administration of a questionnaire [29]. Participants responded to seven questions in the questionnaire, making it possible to determine how many times each had forgotten to take his or her medication. The questionnaire was constructed in such a way that the respondent was placed in a context where events and situations could have led to forgetfulness. Individuals were considered as being adherent if the number of times they forgot the medication was $5 \%$ or less than the number of pills to be taken over seven days (i.e., 95\% adherence). The " $95 \%$ rule" for adherence has been established by Paterson, Swindells, Mohr et al. [28] the as the fundamental standard. The questionnaire has been validated against changes in viral load (sensitivity $71 \%$, specificity $72 \%$, correct classification 


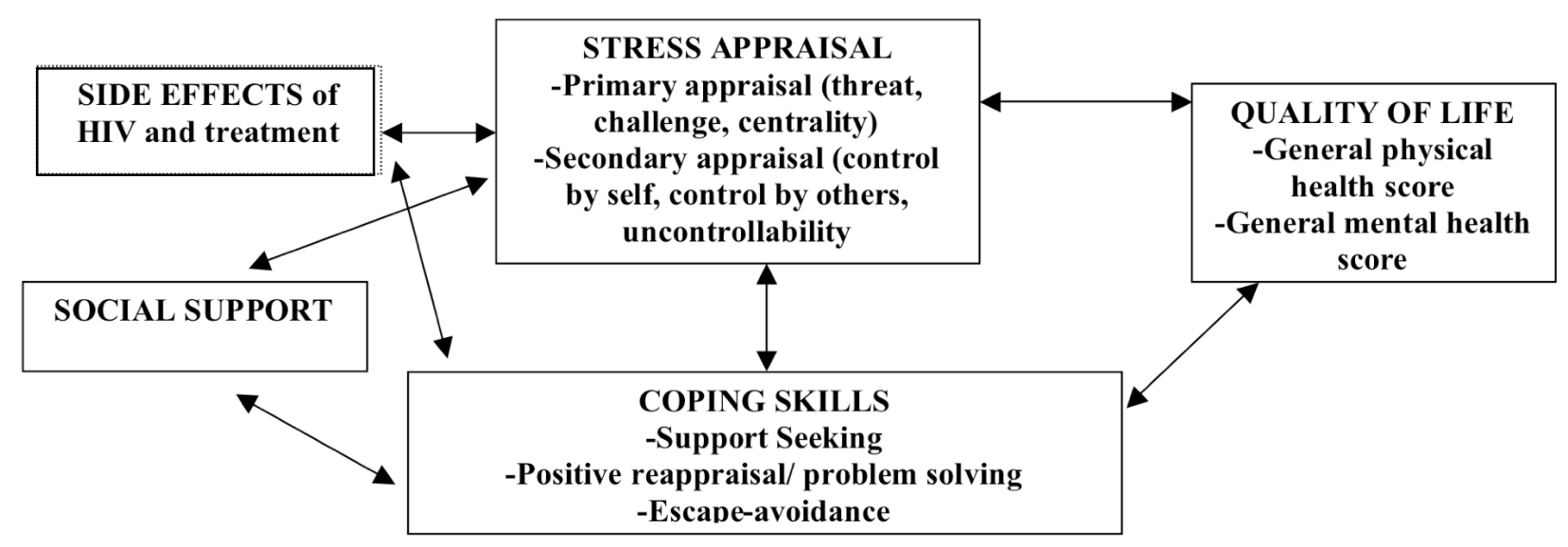

Fig. (1). Relationships between the selected variables under the stress/coping model.

$72 \%$, odds ratio 6.15) [29]. Viral load is an indirect measurement of adherence in as much as, when a person is adherent, his or her viral load is undetectable or less than 50 copies/ml of plasma (viral load: plasma HIV RNA is measured using the $b$ DNA method and the limit of detection of the test is 50 copies/ml of plasma) [30, 31].

\section{Instruments for Measuring the Variables}

Side-effects of HIV and treatment were measured with the 20-item HIV Symptom Index, developed by Justice, Holmes, Gifford et al. [32]. The scale examines both the frequency and the number of physical symptoms, as well as the degree of discomfort caused. This instrument is easy to use and has demonstrated appreciable psychometric properties, including good construct validity. The Cronbach Alpha coefficient was also 0.83 for this study.

Social support was measured with the Social Provision Scale [33], which is composed of 24 items, measuring six dimensions of social support (attachment, reliable alliance, guidance, social integration, reassurance of worth and nurturance) on five-point scales. It has been validated in a sample of 1792 persons and has been used with HIV clientele [34]. This tool has demonstrated appreciable discriminant and concurrent validities, as well as internal consistency (varying to .85 and .92 according to different studies). For this study, internal consistency of the scale was 0.84 .

Stress in people living with HIV was measured with the Stress Appraisal Measure scale (SAM) developed by Peacock and Wong [35]. This instrument assesses three dimensions of primary appraisal: threat, challenge and centrality. Secondary appraisal is also measured for three dimensions: control by self, control by others and uncontrollability (lack of control). In addition, in order to examine the relationship between these dimensions of stress appraisal and the overall stress process, Peacock and Wong elaborated a 'stressfulness' subscale which reflects an overall appraisal of stress. This scale consists of 28 items and seven subscales. Responses are chosen on a five-point Likert scale (1: not at all -5 : too much). Its psychometric properties are satisfactory, including good construct validity and internal consistency with Alpha ranging from 0.74 and 0.90 for these subscales. The Cronbach Alpha coefficient observed on administration of the questionnaire ranged from 0.83 to 0.84 for the various dimensions.

Coping strategies were measured with an abridged version of the Ways of Coping Questionnaire developed by Lazarus and Folkman [26]. This three-dimensional scale of 21 items comprises three sub-dimensions: social support seeking, positive reappraisal/problem solving, and distancing/avoidance. The psychometric properties are satisfactory, including internal consistency ( 0.76 for distancing/avoidance, 0.85 for social support seeking and 0.80 for positive reappraisal/problem solving). The Cronbach Alpha coefficient for all three dimensions of this study ranged from 0.83 to 0.84 .

Quality of life was measured using the Medical Outcome Study-HIV scale from Wu and colleagues [36]. This scale is composed of 35 questions that assess 11 aspects of health in persons living with HIV: general health perceptions, pain, physical functioning, role functioning, social functioning, mental health, energy, health distress, cognitive functioning, quality of life and health transition. The scale thus yields an overall score for physical health and for mental health. More specifically, physical health status (PHS) consists of physical functioning, pain, role functioning, social functioning and general health. Similarly, mental health status (MHS) includes the energy, cognitive functioning, quality of life, health distress and mental health dimensions. The psychometric properties of both the overall scale and its subscales are satisfactory. Wu, Revicki, Jacobson and Malitz [37] reported Cronbach Alpha coefficients over 0.78 for all subscales. For our study, Cronbach Alpha coefficients ranged from 0.83 to 0.85 .

We obtained the following sociodemographic information with a questionnaire: gender, age, level of education and employment status. This questionnaire also included questions related to HIV infection, such as length of time they had been aware they were seropositive, drug treatment and duration of treatment.

\section{Data Collection}

The process of data collection was largely based on Dillman's [38] recommendations for facilitating staff involvement, thus maximizing the participation rate. At the time of their medical visit or of a day hospitalization, the physician gives the patients an information sheet about the study and a document relating the ethical requirements in 
force (anonymity of the respondent as well as voluntary participation). The participants were entirely free to participate and those who did want to were asked to sign 'informed consent' forms. Approval for the study was obtained from the Commission Nationale de l'Informatique et Liberté (CNIL). After complying with the usual ethical requirements (anonymity, voluntary participation), a selfreport survey was given to participants: this consisted of five measurement scales and a sociodemographic questionnaire. In all, they had to complete three self-report questionnaires: at baseline, six (M6) and 12 months (M12). If necessary, participants were able to ask a pre-identified associate in each center for clarifications on the questionnaire. Five percent of respondents required this support. Respondents took between 30 and 45 minutes to fill out the questionnaire. Ultimately, $89 \%$ of the questionnaires were fully completed and available for analysis.

\section{Data Analysis}

First, we used descriptive statistics such as frequency distributions and measurements of central tendency and dispersion to describe the characteristics of the selected sample and the variables of interest. We then performed correlation analysis to explore the existence of the relationships between the variables of interest, as proposed in the Lazarus and Folkman [26] theoretical model (Fig. 1). Finally, multivariate stepwise linear regression determined the variables predicting quality of life in persons living with HIV. All analyses were carried out using SAS software. A critical level of less than .005 was considered as statistically significant.

\section{RESULTS}

\section{Descriptive Characteristics}

The sample was composed predominantly of men, with a mean age of 43 years. Participants had been aware of their seropositivity for a mean of 11.45 years and had been receiving treatment for a mean of 8.67 years. Descriptive statistics for variables of interest are presented in Tables 1 \& 2. Participants had moderate scores on Global Stress (2.18 on a scale of 1 to 5-too much). Participants reported high scores on the Social Support scale: the overall score was 91.28 (on a scale of 24 to 120). For Side-effects, the overall score observed was 1.61 , on a scale of $0-3$. Two-thirds of the sample stated they had moderate discomfort as a result of at least one side-effect. The strategies most often used were Positive Reappraisal/Problem Solving, followed by Escape or Avoidance, with Support Seeking being last. However, the difference between the means of the various strategies was minimal. Consequently, participants made alternate use of these three strategies to face the stressful situations arising from living with HIV. Finally, results related to quality of life yielded very similar Physical Health and Mental Health scores, lying within the mean.

\section{Relationships Between the Variables}

As proposed in the Lazarus and Folkman [26] theoretical model, we first studied the relationships between Side Effects, Social Support and Stress/Coping (Table 3), followed by those between Stress and Coping (Table 4). Relationships between the different variables we retained and the two dimensions of quality of life are displayed in Table $\mathbf{5}$.
Table1. Main Features of the Study Population (N=133)

\begin{tabular}{|c|c|c|c|}
\hline Variables & $\mathbf{M}$ & SD & N (\%) \\
\hline \multicolumn{4}{|l|}{ Socio-Demographics } \\
\hline \multicolumn{4}{|l|}{ Gender } \\
\hline Men & & & $97(72.8 \%)$ \\
\hline Women & & & $36(27.2 \%)$ \\
\hline \multicolumn{4}{|l|}{ Level of education } \\
\hline Elementary & & & $19(15.08 \%)$ \\
\hline High School & & & $68(53.97 \%)$ \\
\hline University & & & $39(30.95 \%)$ \\
\hline \multicolumn{4}{|l|}{ Working Situation } \\
\hline Employed & & & $74(58.73 \%)$ \\
\hline Unemployed & & & $40(31.75 \%)$ \\
\hline Retired & & & $12(9.52 \%)$ \\
\hline Age & 43 & 11 & \\
\hline Time since HIV & 11.45 & 9.1 & \\
\hline Duration of treatment & 8.67 & 3 & \\
\hline \multicolumn{4}{|l|}{ Living alone } \\
\hline No & & & $72(57.1 \%)$ \\
\hline Yes & & & $54(42.9 \%)$ \\
\hline
\end{tabular}

There was a positive relationship between Side effects and the global Stress scores $(r=0.47, p<0.001)$. As well, we observed a positive relationship between the global scores for Side Effects and Escape/Avoidance strategies $(r=$ $0.39, p<0.001)$. The global score for Social Support was associated negatively with Stress $(r=-0.43, p<0.001)$ and positively with strategies for Reappraisal/Problem Solving $(r$ $=0.25, p<0.005)($ Table 3). Also, analysis revealed that notions of Challenge $(r=0.40, p<0.001)$ and Control by Self $(r=0.32, p<0.001)$ were positively related to Positive Reappraisal/Problem Solving strategies (Table 4).

Finally, analysis of the relationships between the various variables we retained and the two quality of life dimensions (PHS, MHS) (Table 5) showed that there was a positive relationship between the Physical Health score and Social support $(r=0.35 . p<0.001)$ and a negative relationship with both Stress $(r=-0.50, p<0.001)$, Side Effects $(r=-0.67, p<$ $0.001)$ and Escape/Avoidance strategies $(r=-0.26, p<$ $0.003)$. We observed negative relationships between Mental Health and Escape/Avoidance strategies $(r=-0.34, p<$ $0.001)$, Stress $(r=-0.70, p<0.001)$ and Side Effects $(r=-$ $0.68, p<0.001)$; however, there was a positive relationship with Social Support $(r=0.58, p<0.001)$.

\section{Explanatory Factors of Quality of Life}

Following the results obtained for the different variables studied, we performed stepwise multiple regression analysis to examine their relation to the outcome variable. We took two dimensions of Quality of Life - Mental Health Status and Physical Health Status - as dependent variables. All 
Table 2 Main Features of the Study Population $(n=133)$

\begin{tabular}{|c|c|c|}
\hline Variables & Mean & SD \\
\hline \multicolumn{3}{|l|}{ Stress appraisal (1) } \\
\hline Threat & 2.33 & 0.93 \\
\hline Challenge & 3.59 & 0.78 \\
\hline Centrality & 3.07 & 1.09 \\
\hline Control by self & 3.68 & 0.77 \\
\hline Control by others & 3.42 & 0.74 \\
\hline Uncontrollability & 1.88 & 0.79 \\
\hline Stress (overall appraisal) & 2.18 & 0.70 \\
\hline \multicolumn{3}{|l|}{ Social support (2) } \\
\hline Overall score & 91.28 & 8.8 \\
\hline Attachment & 15.4 & 3.68 \\
\hline Reliable alliance & 16.83 & 2.88 \\
\hline Guidance & 13.72 & 2.2 \\
\hline Social integration & 14.68 & 3.2 \\
\hline Reassurance of worth & 15.0 & 3.03 \\
\hline Nurturance & 15.55 & 2.94 \\
\hline \multicolumn{3}{|l|}{ Side effects (3) } \\
\hline Fatigue & 2.13 & 0.63 \\
\hline Anxiety & 1.88 & 0.69 \\
\hline Sexual problems & 1.87 & 0.78 \\
\hline Difficulty in sleeping & 1.80 & 0.71 \\
\hline Fever & 1.42 & 0.65 \\
\hline Dizziness & 1.40 & 0.64 \\
\hline Respiratory problems & 1.39 & 0.63 \\
\hline Loss of appetite & 1.34 & 0.59 \\
\hline Overall score & 1.61 & 0.38 \\
\hline \multicolumn{3}{|l|}{ Coping strategies (4) } \\
\hline Support seeking & 2.05 & 0.7 \\
\hline Positive reappraisal/Problem-solving & 2.51 & 0.69 \\
\hline Escape/Avoidance & 2.12 & 0.71 \\
\hline \multicolumn{3}{|l|}{ Quality of life (5) } \\
\hline General physical health score & 51.57 & 9 \\
\hline General mental health score & 50.13 & 9.54 \\
\hline Perceived general health & 52.54 & 20.4 \\
\hline Pain & 76.2 & 24.00 \\
\hline Physical functioning & 81.22 & 22.55 \\
\hline Role functioning & 79.37 & 35.93 \\
\hline Social functioning & 82.54 & 22.91 \\
\hline Mental health & 66.64 & 19.39 \\
\hline Energy & 63.73 & 19.69 \\
\hline Health distress & 81.35 & 22.06 \\
\hline Cognitive functioning & 76.51 & 22.33 \\
\hline Quality of life & 70.64 & 19.26 \\
\hline Health transition & 53.18 & 12.24 \\
\hline
\end{tabular}

variables associated with quality of life at the threshold of 0.2 in bivariate analysis were entered in the logistic regression model. The explanatory variables included in the statistical model were Side Effects, Social Support, Perceived Stress and Coping strategies. These psychosocial variables explained $69 \%$ of Mental health status variance: Perceived Stress (53\%), Side Effects (9\%), Social Support (5\%) and Positive Reappraisal/Problem Solving Strategies (2\%) (Table 6). Physical Health Status, one dimension of Quality of Life, has been explained by Side Effect (39\%), Stress (4\%) and Positive Reappraisal/Problem Solving Strategies (2\%) (Table 7).

\section{DISCUSSION}

The criteria for the selection of this cohort combined two adherence indicators: a viral load of 50 copies or less and an adherence level of $95 \%$ or more, as self-reported on the questionnaire. Our interest in this cohort of persons who were treatment-adherent at inclusion and whose treatment was successful, was to draw up a descriptive psychosocial portrait of their characteristics and to explore explanatory factors for Quality of Life.

On average, the participants in our study had been seropositive for 12 years and had been receiving treatment for nine years. This latter figure coincides with the advent of tri-therapy. The psychosocial profile of the cohort showed that participants had moderate levels of stress, used a varied repertoire of coping strategies to adjust to their situations and enjoyed good peer support. They assessed their quality of life as moderate in both physical and psychological domains. Scores for Stress and Quality of Life that we obtained were similar to those reported by Ruano [39] in a population living with HIV in Spain. However, our global score for Social Support (91.3) is greater than that reported by Godin Côté, Naccache, Lambert and Trottier [34] in their cohort of 400 people receiving antiretroviral therapy in Quebec.

Quality of life in the psychological domain is largely dependent on perceived stress, which explains a large part of the variance. Perceived stress refers to overall stress, of which, as theoretically conceptualized by Lazarus and Folkman [26] there are two elements: primary appraisal and secondary appraisal. In relation to stress appraisal, a closer analysis showed that respondents who perceived difficult situations as a challenge (primary appraisal) and had a perception of control (secondary appraisal) were more likely to use positive reappraisal and problem-solving strategies. The aspect of control is an important component in the process by which the individual copes with and adjusts to the stressors of daily life. If the individual living with HIV perceives the situation as a challenge, and one which can be controlled, he or she tends to use active coping strategies to deal with stress situations that could affect quality of life. Weaver and colleagues [20] found that cognitive coping strategies are related to quality of life and their influence appears to be mediated through perceptions of life stressfulness. Taking into account the preponderance of stress in explaining the psychological component of quality of life, it is essential that the interventions delivered should provide the person living with HIV with the means of managing difficult situations. 
Table 3 Correlations Between Side Effects, Social Support and Stress/Coping Skills

\begin{tabular}{|c|c|c|c|c|}
\hline Variables & Stress (Overall Appraisal & Support Seeking & Positive Reappraisal/Problem Solving & Escape-Avoidance \\
\hline \hline Side effects (overall score) & $0.47^{* *}$ & NS & NS & $0.39^{* *}$ \\
\hline Social support (overall score) & $-0.43^{* *}$ & NS & $0.25^{*}$ & NS \\
\hline
\end{tabular}

${ }^{*} \mathrm{p}<0.005,{ }^{* *} \mathrm{p}<0.001$.

Table 4 Correlations Between Stress and Coping Skills

\begin{tabular}{|l|c|c|c|}
\hline \multicolumn{1}{|l|}{ Variables } & $\begin{array}{c}\text { Support } \\
\text { Seeking }\end{array}$ & $\begin{array}{c}\text { Positive Reappraisal/ } \\
\text { Problem Solving }\end{array}$ & $\begin{array}{c}\text { Escape- } \\
\text { Avoidance }\end{array}$ \\
\hline \hline \multicolumn{3}{|l}{ Stress Appraisal } \\
\hline Threat & NS & NS & NS \\
\hline Challenge & NS & $0.40 *$ & NS \\
\hline Centrality & NS & NS & NS \\
\hline Control by self & NS & $0.32^{*}$ & NS \\
\hline Control by others & NS & NS & NS \\
\hline Uncontrollability & NS & NS & NS \\
\hline Stress (overall appraisal) & NS & NS & NS \\
\hline
\end{tabular}

Table 5 Correlations Between Coping, Stress, Side effects, Social Support and Quality of Life

\begin{tabular}{|c|c|c|}
\hline Variables & $\begin{array}{c}\text { Quality of } \\
\text { Life (PHS) }\end{array}$ & $\begin{array}{c}\text { Quality of } \\
\text { Life (MHS) }\end{array}$ \\
\hline \hline Support seeking & NS & NS \\
\hline Positive reappraisal/Problem solving & NS & NS \\
\hline Escape - avoidance & $-0.26^{*}$ & $-0.34^{* *}$ \\
\hline Stress (overall appraisal) & $-0.50^{* *}$ & $-0.70^{* *}$ \\
\hline Side effects (overall score) & $-0.67^{* *}$ & $-0.68^{* *}$ \\
\hline Social support (overall score) & $0.35^{* *}$ & $0.58^{* *}$ \\
\hline$* \mathrm{p}<0.003,{ }^{* *} \mathrm{p}<0.001$. & \multicolumn{2}{|l}{}
\end{tabular}

Quality of life in the physical domain is largely a function of side effects: this explains a large part of the variance. This finding is corroborated by others $[40,41]$ who have reported that quality of life was worse and deteriorated more rapidly among persons who have more physical symptoms. According to Burgoyne and Tan [42] the deteriorations in quality of life that are due to illness symptoms in the pre-ART treatment era may have been replaced by important deterioration arising from side effects in the ART era. In relation to side effect, a closer analysis showed that when respondents experienced a side-effect, they experienced more stress and tended to deny or to escape from it, rather than face up to it. It is plausible that the presence of symptoms is perceived as stressful and difficult to modify, and that, when confronted by this situation, cognitive distancing strategies are used. As we know, side effects can be better managed; therefore, support interventions should be provided with this aim in mind. Participants were bothered by fatigue, which was the most frequent symptom and caused them the most problems. Johnson and colleagues [43] and Vogl and collegues [44] also observed that fatigue was the symptom most often reported, affecting about $85 \%$ of their sample. Fatigue is linked with multiple factors: an advanced stage of the disease, opportunistic infections, poor nutritional status, and treatment with antiretroviral drugs, hormone deficiency and anaemia. It is one of the most common clinical symptoms affecting quality of life in HIV-positive persons [45] and should not be overlooked or minimized as a symptom of chronic HIV infection. It should be systematically evaluated and addressed, even in successfully treated, adherent persons.

Our intention in this study was also to examine the relationships between the Stress-Coping tandem and other variables, notably Social Support. Our findings show that those who perceive themselves as having a high level of support are more likely to experience less stress and use positive reappraisal and problem-solving strategies. The presence of a comforting, effective social network appears to enable the individual to confront and analyze difficult situations in a positive way. The literature documents the buffering effect of social support in the adjustment process [46] and in health behaviours - in this instance, treatment adherence [47, 48]. In the adjustment process, support is seen as a coping resource that gives the individual access to a varied repertoire of strategies. Burgoyne and Renwick [14] examined the interplay between social support and quality of life in a cohort of persons living with HIV. They found that self-perceived quality of life is indeed mediated by social

Table 6 Multiple Regression Analysis: Predictors of Quality of Life (MHS)

\begin{tabular}{|c|c|c|c|c|c|}
\hline Explanatory Variables & BETA & B Standardise & R2 & Cumulative R-Square & p \\
\hline \hline Stress (overall appraisal) & -5.4 & -0.46 & 0.53 & 0.53 & $\mathrm{p}<0.0001$ \\
\hline Side effects & -0.4 & -0.31 & 0.09 & 0.62 & $\mathrm{p}<0.0001$ \\
\hline Social support & 4.1 & 0.23 & 0.05 & 0.67 & $\mathrm{p}<0.0001$ \\
\hline Positive reappraisal/Problem solving & 1.75 & 0.12 & 0.02 & 0.69 \\
\hline
\end{tabular}


Table 7 Multiple Regression Analysis: Predictors of Quality of Life (PHS)

\begin{tabular}{|l|c|c|c|c|c|}
\hline \multicolumn{1}{|c|}{ Explanatory Variables } & BETA & B Standardise & R2 & Cumulative R-Square & p \\
\hline \hline Side effects & -0.63 & -0.54 & 0.39 & 0.4 & $\mathrm{p}<0.0001$ \\
\hline Stress (overall appraisal) & -2.17 & -0.20 & 0.04 & 0.44 & $\mathrm{p}=0.006$ \\
\hline Positive reappraisal/Problem solving & 0.97 & 0.15 & 0.02 & 0.45 & 0.03 \\
\hline
\end{tabular}

support. Also, Liu, Johnson, Ostrow, Silvestre, Visscher and Jacobson [18] and Jia [17] have shown that social support is a very important factor for patients' mental health quality of life. Social support, as a coping resource, should therefore be taken into account in the delivery and follow-up of interventions to increase quality of life for these clients.

This study has documented relationship between quality of life and stress experienced, discomfort reported from HIV-associated symptoms and treatment, perceived social support, coping strategies used among a cohort of successfully treated patients in France living with HIV. However, our study has some limitations. Because of its cross sectional design, it provides a portrait of the situation at a given point in time and makes no allowance for any direction or causality in the relationships examined. The findings therefore appear more exploratory than confirmatory. Also, our findings are thus limited to the population studied, which, at the time of participation, were characterized by optimal adherence and successful treatment. We have gained an understanding of the contributing role of perceived stress and perceived side effect in the mental and physical domains of quality of life and that these are two important factors to target in our interventions for improving quality of life. As well, in the relationship between perceived social support and the stress-coping tandem, social support is an important coping resource that should be taken into account in the development and delivery of interventions.

In the course of taking antiretrovirals, nurses are called upon to take a preponderant role among persons living with HIV. Effectively, the nurse occupies a strategic position from which she or he can present information on the antiretroviral therapy, while being able to evaluate the stress being experienced and support resources available. In this way, the nurse can assist the individual to manage stress more effectively and to mobilize support. Very delicate or fragile individuals (high stress level, isolated) thus are able to take advantage of a more intense follow-up from the health care team. It is important to evaluate the secondary effects connected with the therapy that the individual perceives as the most troublesome, and to offer them strategies to help them cope.

\section{CONCLUSION}

As well as giving a picture of treatment-adherent, successfully-treated persons living with HIV, our study enabled us to examine the variables associate to their quality of life. According to $\mathrm{Wu}$ [49] in order to ensure a high level of adherence, it is essential to optimize the quality of life of persons living with HIV. Mannheimer and colleagues [9] have demonstrated that persons with optimal adherence have better quality of life after one year, if optimal adherence has been maintained over that period. However, the nature of the relationship between quality of life and treatment adherence is still ambiguous and further studies are necessary [50, 51]. As such, we are performing a longitudinal follow-up of this cohort of treatment-adherent, successfully-treated persons, so that we can examine the dual link of adherence and quality of life more closely.

\section{ACKNOWLEDGEMENTS}

The authors wish to thank Professor Massip, Director of the Department of Infectious Diseases, Centre Hospitalier Universitaire de Toulouse, for his close collaboration. As well, we thank the medical practitioners of the MidiPyrénées region who participated, and the heads of the healthcare services, management staff, and nurses who enabled this research project to be set up and followed through. The research team also thank Ms. Pronost, Ms. Tourette-Turgis and Dr. Spire for their helpful advice. This study was funded by the regional Hospital Programme for Clinical Research (PHRC).

\section{REFERENCES}

[1] Joint United Nations Programme on HIV/AIDS. Report on the global AIDS epidemic. 2008 [updated 2008; cited 2009 February 24]; Available from: http://www.unaids.org/en/KnowledgeCentre/ HIVData/GlobalReport/2008/2008_Global_report.asp.

[2] Kraaij V, Van Der Veek S, Garnefski N, Schroevers M, Witlox R, Maes S. Coping, goal adjustment, and psychological well-being in HIV-infected men who have sex with men. AIDS Patient Care STDS 2008; 22(5): 395-402.

[3] Fields-Gardner C, Keithley JK. Management of antiretroviralrelated nutritional problems: challenges and future directions. J Assoc Nurses AIDS Care 2001; 12(Suppl 1): 79-84.

[4] Bangsberg DR, Hecht FM, Charlebois ED, et al. Adherence to protease inhibitors, HIV-1 viral load, and development of drug resistance in an indigent population. AIDS 2000; 14(4): 357-66.

[5] Conway BMD. The role of adherence to antiretroviral therapy in the management of HIV infection. J Acquir Immune Defic Syndr 2007; 45(Suppl 1): S14-S8.

[6] Pakenham KI, Renaldis M. The role of illness, resources, appraisal and coping strategies in adjustment to HIV/AIDS: the direct and buffering effect. J Behav Med 2001; 24(3): 259-79.

[7] Au A, Chan I, Li P, Chung R, Po LM, Yu P. Stress and healthrelated quality of life among HIV-infected persons in Hong Kong. AIDS Behav 2004; 8(2): 119-29.

[8] Johnson MO, Catz SL, Remien RH, et al. Theory-guided, empirically supported avenues for intervention on HIV medication nonadherence: findings from the healthy living project. AIDS Patient Care STDS 2003; 17(12): 645-56.

[9] Mannheimer S, Matts J, Telzak E, et al. Quality of life in HIV infected individuals receiving antiretroviral therapy is related to adherence. AIDS Care 2005; 17(1): 10-22.

[10] Lenderking WR, Gelber RD, Cotton DJ, et al. Evaluation of the quality of life associated with zidovudine treatment in asymptomatic human HIV. N Engl J Med 1994; 330: 738-43.

[11] Scott-Lennox JA, Mills RJ, Burt MS. Impact of zidovudine plus lamivudine or zalcitabine on health-related quality of life. Ann Pharmacother 1998; 32: 525-9.

[12] Burgoyne RW, Rourke SB, Behrens DM, Salit IE. Long-term quality-of-life outcomes among adults living with $\mathrm{HIV}$ in the 
HAART era: the interplay of changes in clinical factors and symptom profile. AIDS Behav 2004; 8(2): 151-63.

[13] Stangl AL, Wamai N, Mermin J, Awor AC, Bunnell RE. Trends and predictors of quality of life among HIV-infected adults taking highly active antiretroviral therapy in rural Uganda. AIDS Care 2007; 19(5): 626-36.

[14] Burgoyne R, Renwick R. Social support and quality of life over time among adults living with HIV in the HAART era. Soc Sci Med 2004; 58: 1353-66.

[15] Jia H, Uphold CR, Wu S, Chen GJ, Duncan PW. Predictors of changes in health-related quality of life among men with HIV infection in the HAART era. AIDS Patient Care STDS 2005; 19: 395-405.

[16] Jia H, Uphold CR, Wu S, Reid K, Findley K, Duncan PW. Healthrelated quality of life among men with HIV infection: Effects of social support, coping and depression. AIDS Patient Care STDS 2004; 18: 594-603.

[17] Jia H, Uphold CR, Zheng Y, et al. A further investigation of healthrelated quality of life over time among men with HIV infection in the HAART era. Qual Life Res 2007; 16: 961-8.

[18] Liu C, Johnson L, Ostrow D, Silvestre A, Visscher B, Jacobson LP. Predictors for lower quality of life in the HAART era among HIVinfected men. J Acquir Immune Defic Syndr 2006; 42(4): 470-7.

[19] Vosvick M, Gore-Felton C, Koopman C, Thoresen C, Krumboltz J, Spiegle D. Maladaptive coping strategies in relation to quality of life among HIV+ adults. AIDS Behav 2002; 6(1): 97-106.

[20] Weaver KE, Antoni MH, Lechner SC, et al. Perceived stress mediates the effects of coping on the quality of life of HIV-positive women on highly active antiretroviral therapy. AIDS Behav 2004; 8(2): 175-83.

[21] Kemppainen JK. Predictors of quality of life in AIDS. J Assoc Nurses AIDS Care 2001; 12(1): 61-70.

[22] Tate D, Paul RH, Flanigan TP, et al. The impact of apathy and depression on quality of life in patients infected with HIV. AIDS Patient Care STDS 2003; 17: 115-20.

[23] Lubeck DP, Fries JF. Health status among persons infected with HIV: a community-based study. Med Care 1993; 31: 269-76.

[24] Tsevat J, Solzan JG, Kuntz KM, et al. Health values of patients infected with HIV. Med Care 1996; 34: 44-57.

[25] Murri R, Fantoni M, Del Borgo C, et al. Determinants of healthrelated quality of life in HIV-infected patients. AIDS Care 2003; 15(4): 581-90.

[26] Lazarus RS, Folkman S. Stress, appraisal and coping. New York: McGraw-Hill 1984.

[27] Delfraissy JF. Prise en charge thérapeutique des personnes infectées par le VIH. Paris: Flammarion; 2004 [updated 2004; cited 2008 June 9]; Available from: http://lesrapports.ladocumentation francaise.fr/BRP/044000467/0000.pdf

[28] Paterson D, Swindells S, Mohr J, et al. Adherence to protease inhibitor therapy and outcomes in patients with HIV infection. Ann Intern Med 2000; 133(1): 21-30.

[29] Godin G, Gagné C, Naccache H. Validation of a self-reported questionnaire assessing adherence to antiretroviral medication. AIDS Patient Care STDS 2003; 17: 325-32.

[30] Maggiolo F, Ravasio L, Ripamonti D, et al. Similar adherence rates favor different virologic outcomes for patients treated with nonnucleoside analogues or protease inhibitors. Clin Infect Dis 2005; 40(1): 158-63.

[31] Nachega JB, Hislop M, Dowdy DW, Chaisson RE, Regensberg L, Maartens G. Adherence to nonnucleoside reverse transcriptase inhibitor based HIV therapy and virologic outcomes. Ann Intern Med 2007; 146(8): 564-73.
[32] Justice AC, Holmes W, Gifford AL, et al. Development and validation of a self-completed HIV symptom index. J Clin Epidemiol 2001; 54(12 Suppl 1): S77-S90.

[33] Cutrona CE, Russel DW. The provisions of social support and adaptation to stress. Adv Pers Relat 1987; 1: 37-67.

[34] Godin G, Côté J, Naccache H, Lambert LD, Trottier S. Predictors of adherence to antiretroviral therapy: a one year longitudinal study. AIDS Care 2005; 17: 493-504.

[35] Peacock EJ, Wong PTP. The stress appraisal measures: a multidimensional approach to cognitive appraisal. Stress Med 1990; 6: 227-36

[36] Wu AW, Rubin HR, Mathews WC, et al. A health status questionnaire using 30 items from the medical outcomes study. Preliminary validation in persons with early HIV infection. Med Care 1991; 29: 786-98.

[37] Wu AW, Revicki DA, Jacobson D, Malitz FE. Evidence for reliability, validity and usefulness of the medical outcomes study HIV health survey. Qual Life Res 1997; 6: 481-93.

[38] Dillman DA. Mail and telephone surveys: the total design method. New York: Wiley 1978

[39] Ruano OL. Relations between stress appraisal, coping and quality of life among HIV patient in Spain, Master Thesis. Montreal University of Montreal 2002.

[40] Bader A, Kremer H, Erlich-Trungenberger I, et al. An adherence typology: coping, quality of life, and physical symptoms of people living with HIV/AIDS and their adherence to antiretroviral treatment. Med Sci Monit 2006; 12(12): CR493-CR500.

[41] Lorenz KA, Cunningham WE, Spritzer KL, Hays RD. Changes in symptoms and health-related quality of life in a nationally representative sample of adults in treatment for HIV. Qual Life Res 2006; 15: 951-8.

[42] Burgoyne RW, Tan DHS. Prolongation and quality of life for HIV infected adults treated with highly active antiretroviral therapy (HAART): a balancing act. J Antimicrob Chemother 2008; 61: 469-73

[43] Johnson MO, Stallworth T, Neilands TB. The drugs or the disease? causal attributions of symptoms held by HIV-positive adults on HAART. AIDS Behav 2003; 7(1): 109-17.

[44] Vogl D, Rosenfeld B, Breitbart W, et al. Symptom prevalence, characteristics, and distress in AIDS outpatients. J Pain Symptom Manage 1999; 18(4): 253-62.

[45] Adinolfi A. Assessment and treatment of HIV-related fatigue. J Assoc Nurses AIDS Care 2001; 12: 29-34.

[46] Leserman J, Jackson ED, Petitto JM, et al. Progression to AIDS: the effects of stress, depressive symptoms, and social support Psychosom Med 1999; 61: 397-406.

[47] Catz SL, Kelly JA, Bogart LM, Benotosh EG, McAuliffe TL. Patterns, correlates, and barriers to medication adherence among persons prescribed new treatments for HIV disease. Health Psychol 2000; 19(2): 124-33.

[48] Gifford AL, Bormann JE, Shively MJ, Wright BC, Richman DD, Bozette SA. Predictors of self-reported adherence and plasma HIV concentrations in patients on multidrug antiretroviral regimens. J Acquir Immun Defic Syndr 2000; 23: 386-95.

[49] Wu AW. Quality of life assessment comes of age in the era of highly active antiretroviral therapy. AIDS 2000;14: 1449-51.

[50] Carballo E, Cadarso-Suarez C, Carrera I, et al. Assessing relationships between health-related quality of life and adherence to antiretroviral therapy. Qual Life Res 2004; 13: 587-99.

[51] Penedo FJ, Gonzalez JS, Dahn JR, et al. Personnality, quality of life and HAART adherence among men and women living with HIV/AIDS. J Psychosom Res 2003; 54: 271-8. 